\title{
Unknown cause of elevated cardiac troponin concentration in 21-year-old patient
}

\author{
Nieznana przyczyna podwyższenia stężenia troponin sercowych u 21-letniego pacjenta
}

\author{
Agnieszka Kuczaj ${ }^{1}$, Piotr J. Stryjewski ${ }^{2}$, Ewa Nowalany-Kozielska' ${ }^{1}$, Jadwiga Nessler ${ }^{3}$, Jacek Nowak ${ }^{2}$ \\ ${ }^{1} 2^{\text {nd }}$ Department of Cardiology, Zabrze, Medical University of Silesia, Katowice, Poland \\ ${ }^{2}$ Cardiology Department, Chrzanow City Hospital, Chrzanow, Poland \\ ${ }^{3}$ Department of Coronary Disease, Institute of Cardiology, Jagiellonian University Medical College, John Paul II Hospital, Krakow, Poland
}

A 21-year-old patient was admitted to the cardiac ward due to untypical chest pain with concomitant cardiac troponin elevation - TNI $3.381 \mu \mathrm{g} / \mathrm{L}(0-0.04 \mu \mathrm{g} / \mathrm{L})$, CK-MB $21 \mathrm{U} / \mathrm{L}(0-24 \mathrm{U} / \mathrm{L})$. The symptoms occurred for the first time $3 \mathrm{~h}$ before first medical contact and resolved after an empirically administered non-steroidal anti-inflammatory drug. The patient had no comorbidities and regularly trained in endurance sports (walking, football, cycling). He denied use of dietary supplements or psychoactive substances. At the day of symptoms occurrence the patient had no major physical stress or trauma. Family history of cardiovascular diseases was negative. At admission the patient was in good general condition, and his heart rate was regular at $52 \mathrm{bpm}$. His lung and heart sounds were clear; abdomen was soft and non-tender with no organomegaly. Electrocardiogram (ECG) showed normal findings (Fig. 1), without signs of acute or past ischaemia and without typical signs of pericarditis. Echocardiographic examination showed normal heart morphology and function with left ventricular ejection fraction equalling 70\%. Laboratory tests, initiated in order to find the cause of isolated significant cardiac troponin elevation (3.381 $\mu \mathrm{g} / \mathrm{L}$, after $6 \mathrm{~h} 4.623 \mu \mathrm{g} / \mathrm{L}, \mathrm{CK}-\mathrm{MB} 25 \mathrm{U} / \mathrm{L}$, after $6 \mathrm{~h} 21 \mathrm{U} / \mathrm{L})$, showed no changes: WBC $4.7610^{3} / \mu \mathrm{g} / \mathrm{L}, \mathrm{CRP} 0.6 \mathrm{mg} / \mathrm{dL}$, ESR $3 \mathrm{~mm} / \mathrm{h}$, D-Dimer - negative, TSH $1.33 \mu \mathrm{lU} / \mathrm{mL}$, serum creatinine $73 \mu \mathrm{mol} / \mathrm{L}$, Antistreptolysin O titre $100 \mathrm{U}, \mathrm{ANA}$, ANCA, RF - negative. On the basis of preliminary diagnostic findings, other than acute myocardial infarction (AMI), typical causes of troponin elevation were excluded. Due to the troponin dynamics, suggesting AMI coronary, angiography was scheduled. The examination elucidated normal coronary arteries (Figs. 2, 3). During the hospitalisation chest pain episodes recurred several times and resolved after non-steroidal anti-inflammatory drugs. ECG examinations as well as echocardiography carried out during symptom occurrence showed no pathological findings. After 5 days the symptoms spontaneously resolved and titre of cardiac necrosis markers decreased (TNI $0.03 \mu \mathrm{g} / \mathrm{L}, \mathrm{CK}-\mathrm{MB} 13 \mathrm{U} / \mathrm{L}$ ). Cardiac troponins are valuable markers in current diagnostics of AMI. It is important to keep in mind that elevated troponin concentration is a result of cardiac disease, but it can also be elevated in diseases that affect cardiac muscle indirectly, leading to cardiac myocyte injury in variable mechanisms. Its diagnostic value in $\mathrm{AMI}$ should be correlated with clinical history and ECG. Before a diagnostic and therapeutic approach, complex analysis of the clinical case is needed. The presented case illustrates that in some patients the cause of cardiac necrosis marker elevation remains unknown.

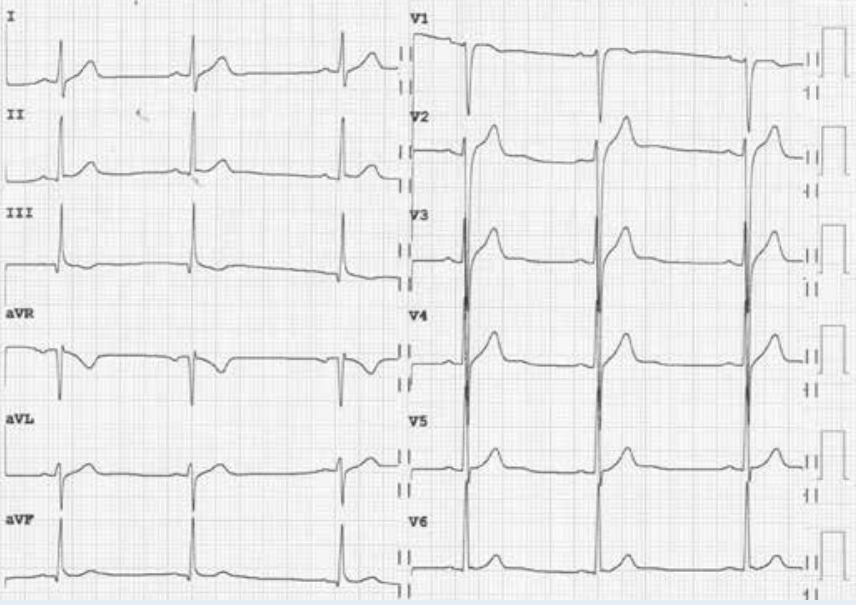

Figure 1. 12-lead ECG (speed $25 \mathrm{~mm} / \mathrm{s}$ and $1 \mathrm{mV} / \mathrm{cm}$ standardisation)

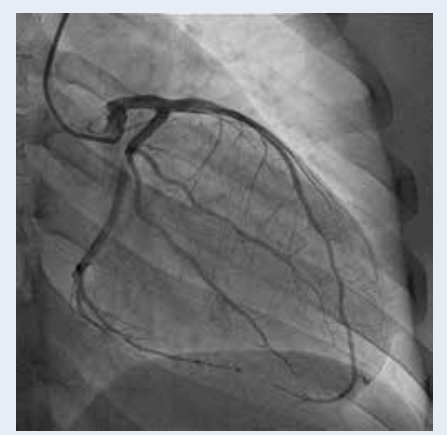

Figure 2. Coronary angiography left coronary artery

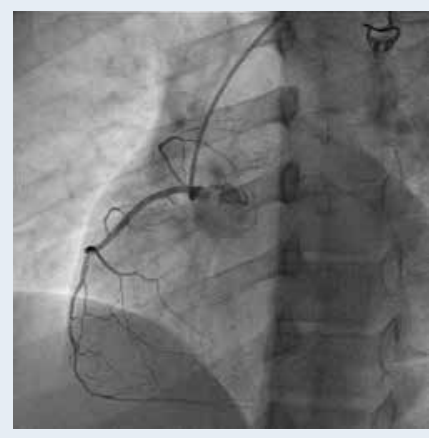

Figure 3. Coronary angiography right coronary artery

\section{Address for correspondence:}

Agnieszka Kuczaj, MD, PhD, $2^{\text {nd }}$ Department of Cardiology, Medical University of Silesia, ul. Marii Curie-Skłodowskiej 9, 41-800 Zabrze, Poland, tel: +48 323732372 , fax: +4832271 10 10, e-mail: agnieszka.kuczaj@gmail.com

Conflict of interest: none declared 